\title{
Chemical composition and insecticidal activity Mentha piperita L. essential oil against the cowpea seed beetle Callosobruchus maculatus F. (Coleoptera: Bruchidae)
}

\author{
K. Saeidi, ${ }^{1}$ S. Mirfakhraie ${ }^{2}$ \\ ${ }^{1}$ Plant Protection Research Department, Fars Agricultural and Natural Resources Research and Education Center, \\ AREEO, Shiraz; ${ }^{2}$ Plant Protection Department, Faculty of Agriculture, Urmia University, Urmia, Iran
}

\begin{abstract}
Antifeedant activity of plant extract from Mentha piperita was tested against the cowpea seed beetle, Callosobruchus maculatus. Dry ground plant was subjected to hydrodistillation using a Clevenger-type apparatus. The resulting oil contained menthone $(28.9 \%)$, menthol $(28.5 \%)$, and pulegone $(6.9 \%)$ as the major compounds. $\mathrm{LC}_{50}$ of $M$. piperita essential oil was $25.70 \mu \mathrm{L} / \mathrm{L}$ air and mortality increased as the doses of essential oil increased. $\mathrm{LT}_{50}$ values were $3.29,2.74$ and $1.89 \mathrm{~h}$ at 100,200 and 500 $\mu \mathrm{L} / \mathrm{L}$ air, respectively. The results of persistence test of oil revealed that essential oil of $M$. piperita on C. maculatus adults was 5.44 days. It was clear from the repellency index that M. piperita essential oil has strong repellency at 90 , 180 and $360 \mu \mathrm{L} / \mathrm{L}$ air concentration. The results showed that M. piperita essential oil has significantly affected the
\end{abstract}

\footnotetext{
Correspondence: Shahram Mirfakhraie, Plant Protection Department, Faculty of Agriculture, Urmia University, Urmia, Iran.

E-mail: sh_mirfakhraie@yahoo.com

Key words: essential oil, Mentha piperita, fumigant toxicity, repellency, persistence, nutritional indices, Callosobruchus maculatus.

Contributions: the authors contributed equally.

Conflict of interest: the authors declare no potential conflict of interest.

Received for publication: 29 April 2017.

Revision received: 29 May 2017.

Accepted for publication: 29 May 2017.

CCopyright K. Saeidi and S. Mirfakhraie, 2017

Licensee PAGEPress, Italy

Journal of Entomological and Acarological Research 2017; 49:6769

doi:10.4081/jear.2017.6769
}

This article is distributed under the terms of the Creative Commons Attribution Noncommercial License (by-nc 4.0) which permits any noncommercial use, distribution, and reproduction in any medium, provided the original author(s) and source are credited. relative growth rate, relative consumption rate and feeding deterrence index of $C$. maculatus adults and it was concentration-dependent. The efficiency of conversion of ingested food has decreased while the concentrations are not statistically different at $5 \%$ level compared to the control group. It seems that essential oil can be used as low-risk insecticides.

\section{Introduction}

Insect pests are one of the main causes of extensive damage in stored grains and their products. Universal pest damage to the stored products is 10 to $40 \%$ (Park et al., 2008; Aliakbari et al., 2010). Among these pests, coleopteran stored pests are the fiercest pests that are continually reproductive and extremely high generation in optimal conditions. The stored pest can damage to the agricultural products in a short time (Arthur et al., 1990; Ayvaz et al., 2010).

The cowpea seed beetle, Callosobruchus maculatus (Fab.) (Coleoptera: Chrysomelidae: Bruchinae) is a major pest of economically important leguminous grains, such as cowpeas, lentils, green gram, and black gram (Benhalima et al., 2004; Benzi et al., 2009; Halder et al., 2010). They are important pests of pulse crops in Asia and Africa under storage conditions (Arthur et al., 1991; Huang et al., 2000; Ali \& Rizvi, 2008; Ebadollahi \& Mahbobi, 2011).

In order to keep these stored grains free from pest attack, various synthetic pesticides have been used (Huang \& Subramanyam, 2005). Synthetic pesticides have been considered the most effective and accessible means of controlling insect pests of stored products (Huang \& Subramanyam, 2005). These chemicals are associated with undesirable effects on the environment due to their slow biodegradation and some toxic residues in products, affecting mammalian health (Benhalima et al., 2004; Isman, 2006; Halder et al., 2010). The adverse effects of synthetic pesticides have amplified the need for an effective and biodegradable pesticide. The control of this pest in storage systems mainly depends on fumigants such as methyl bro- 
mide or phosphine, and fogging with pyrethrins or dichlorvos. However, methyl bromide has been banned in many countries since 2004 because of its ozone depleting properties (Hansen \& Jensen, 2002; Saeidi \& Yousefi, 2013; Saeidi $\&$ Hassanpour, 2014).

Plant secondary metabolites play an important role in plant-insect interactions and therefore such compounds may have insecticidal or biological activity against insects. Natural products are an excellent alternative to synthetic pesticides as a means to reduce negative impacts on human health and the environment. Among the various kinds of natural substances that have received particular attention as natural agents for insect management are essential oils from aromatic plants. Essential oils are renewable, non-persistent in the environment and relatively safe to natural enemies, non-target organisms and human beings (Halder et al., 2010). Effects of essential oils on stored-product insect pests have been reported on extensively (Ogendo et al., 2008; Park et al., 2008; Benzi et al., 2009; Ayvaz et al., 2010; Nayamador et al., 2010; Taghizadeh-Saroukolai et al., 2010).

Natural products are excellent alternatives to synthetic pesticides as a mean to reduce negative impacts on human health and the environment. Essential oils of aromatic plants among the various kinds of natural substances have received particular attention as natural agents for insect management. Plant powders are renewable, non-persistent in the environment and relatively safe to natural enemies, non-target organisms and human beings (Halder et al., 2010). Therefore, botanicals insecticides (plant powders) are used as grain protectants as they have insecticidal properties against stored grain insect pests (Isman \& Machial, 2006; Bahl et al., 2008) as well as being safer for human health and the environment (Warkentin et al. 1991; Rehman et al., 1992). Therefore, the main goal of the present study was to evaluate the insecticidal activity of essential oil M. piperita grown in Iran for the control of $C$. maculatus under laboratory conditions.

\section{Materials and methods}

\section{Rearing of insect}

A culture of the C. maculatus was established on the seeds of unshelled brown cowpea, Vigna ungiculata L. in one litter wide-mouthed glass jars under laboratory conditions. Parent adults were obtained from laboratory stock culture maintained at the Entomology Department, University of Yasouj, Iran. The culture was maintained in the dark (similar to storage conditions) in a growth chamber set at $27 \pm 1^{\circ} \mathrm{C}$ and $65 \pm 5 \%$ relative humidity. All experiments were carried out under the same environmental conditions. The 1-2 days old adults of C. maculatus were used in bioassay tests.

\section{Collected and dried plant specimens}

The leaves of plant known to have medicinal activity, $M$. piperita L. were collected from Kuhgoul which was located in $10 \mathrm{~km}$ distance of Sisakht town, Kohgiluyeh va Boyerahmad province, Iran within spring of 2015. The iden- tity of plant species was verified by Shahabedin Mirinejad (botanical specialist from Agriculture and Natural Resources Researches Center of Kohgiloyeh and Boyerahmad, Yasouj), using live specimens and photographs.

\section{Extraction of essential oils}

Plant material was air dried in the shade at room temperature $\left(26-28^{\circ} \mathrm{C}\right)$ for $20 \mathrm{~d}$ and stored in darkness until distillation. The essential oil was isolated from dried plant sample by hydro-distillation using a Clevenger apparatus. Conditions of extraction were: $50 \mathrm{~g}$ of air-dried sample, 1:10 plant material/water volume ratio, $3 \mathrm{~h}$ distillation. The essential oil was collected, dried over anhydrous sodium sulfate and stored at $4^{\circ} \mathrm{C}$ until use.

\section{Analysis of essential oils}

The oil compositions were analyzed by gas chromatography-mass spectrometry (GC-MS). GC-MS analysis was performed by using a Thermofinnigan Trace GC 2000, equipped with a MS fused silica capillary column $(30 \mathrm{~m} \times$ $0.25 \mathrm{mmi}$. d, film thickness $0.25 \mu \mathrm{m}$ ). For GC-MS detection, an electron ionization system with ionization energy of $200 \mathrm{eV}$ was used. Carrier gas was helium at a flow rate of $1.5 \mathrm{~mL} / \mathrm{min}$. Injector and MS transfer line temperatures were set at 250 and $200^{\circ} \mathrm{C}$, respectively. The oven temperature was programmed from 80 to $250^{\circ} \mathrm{C}$ at $8^{\circ} \mathrm{C} / \mathrm{min}$, then held isothermal for $10 \mathrm{~min}$ and finally raised to $350^{\circ} \mathrm{C}$ at rate of $10^{\circ} \mathrm{C} / \mathrm{min}$. The relative percentage of the oil constituents was expressed as percentages by peak area normalization. The identification of individual compounds of essential oils was based on the comparison of their relative retention times with those of authentic samples on DB-225 capillary column, and by matching of their mass spectra of peaks with those obtained from authentic samples.

\section{Fumigant toxicity}

In order to determine the fumigant toxicity of M. piperita essential oil on adult insects, firstly effective concentrations of essential oil were obtained for the mortality of 20 to $80 \%$ of treated insects during the initial tests. The tests were run in glass cylinder containers having shield with volume of $40 \mathrm{~mL}$ as fumigant chambers. Twenty adult insects were posited in the glass. Concentrations of 20, 25, 30, 35 and 45 $\mu \mathrm{L} / \mathrm{L}$ air from $M$. piperita essential oil were chosen. Then, they were put on filter paper using sampler. Immediately, the glasses were recapped, the sides of the cap were covered with strips so as to prevent the outlet of essential oil. The number of died insects were counted after $24 \mathrm{~h}$. In these experiments, those insect's incapable of moving their heads, antennae and body were considered as dead. This test was treated five times with control groups. All procedure was done for controls without essential oil concentrations.

For studying of lethal time values, three concentrations of 100,200 and $500 \mu \mathrm{L} / \mathrm{L}$ air from M. piperita essential oil higher than $\mathrm{LC}_{50}$ was chosen to be used for analyzing the rate of death. Twenty adults' insects were put into cylinder glasses volume as $40 \mathrm{~mL}$. Mentioned concentrations were 
used on the filter paper which attached inside of glasses caps. In order to prevent the outlet of essential oils, caps of the glasses were covered with strips. This experiment was treated five times with control groups. This means that separate tests were used for each time interval. After the passage of time, the containers were opened and the number of dead insects was counted. Those insect's incapable of moving their heads, legs, antennae and body were considered as dead ones.

In order to determine the persistence of essential oil in fumigant toxicity, four concentrations were used so as to cause higher rates of deaths. The obtained results were only acceptable at the highest concentration from statistic aspect. Cylinder-like capped glasses with $40 \mathrm{ml}$ volume were used. Twenty $\mu 1 /$ lair concentrations of the essential oil were treated on the filter paper inside the glasses caps. The glasses were capped and in order to ascertain the impenetrability of air, they were tightening by strips. This experiment was repeated five other times. Twenty numbers of adult insects were placed in the test glasses after one day of placing essential oil within the glasses, and the numbers of dead insects were counted after $24 \mathrm{~h}$. So, insects aged as three days were added to the containers and the number of dead insects were recounted after $24 \mathrm{~h}$. This trend followed for 5, 7, and etc. days of insects living. The glasses were capped before the transmission of insects and when insects are completely placed in the containers, they were recapped again to be kept until the last moment of treatment. In order to make sure of impenetrability of air into the containers, they were tightening with strips. The persistence of essential oil was evaluated for 15 days and the number of deaths was recorded.

\section{Essential oil repellency}

In order to study the essential oil repellent index, Lopez et al. (2008) method was applied. In doing so, two holes were perforated in two sides of the plastic container and each hole would be connected to the other using $5 \mathrm{~cm}$ pipe. Hence, three plastic containers would be connected and those containers to be put in the sides of the middle one will be considered as control and treated containers. 40 cowpea seeds are placed into the control container on which $1 \mathrm{ml}$ of acetone has been spilled. In the treatment containers, concentration of 2.8, 5.6 and $11.2 \mu \mathrm{L}$ from the essential oil are placed whose ratio is 4:1 to be diluted with acetone. fifty adult insects aged as 1 to 7 days to be kept hungry for $24 \mathrm{~h}$ were placed in the middle container. The containers were capped during the experiment and the number of insects were counted in each container after $24 \mathrm{~h}$ followed by the estimation of repellent index. This test was repeated five times.

Essential oil repellent Index (RI) was calculated as follow: $R I=2 G /(G+P)$. That $G$ is the number of adult insects in treatment area and $\mathrm{P}$ is the number of adult insects in control area. For each calculated RI, the mean and standard deviation were determined. If the mean is lower than 1-SD, essential oil concentration has repellent property. If the man is higher than $1+\mathrm{SD}$, essential oil concentration has attractant property. If the man falls between 1-SD and 1+SD essential oil concentration is neutral.
In order to categorize the repellent effect of essential oils, Tapondjou et al. (2005) method is used. Five groups are considered based on the mean of repellent percent: Class 0: $\mathrm{PR}=0-0.1 \%$, Class I: $\mathrm{PR}=0.1-20 \%$, Class II: $\mathrm{PR}=20.1-40 \%$, Class III: PR $=40.1-60 \%$, Class IV: $P R=60.1-80 \%$ and Class $\mathrm{V}: \mathrm{PR}=80.1-100 \%$.

\section{Flour disk bioassay}

According to the method of Mohandass et al. (2007) a suspension of $10 \mathrm{~g}$ cowpea seed flour in $50 \mathrm{~mL}$ distilled water was prepared. A micropipette was used to transfer 200-mL aliquots from the suspension onto a plastic sheet. After $4 \mathrm{~h}$ at room temperature, the cowpea seed flour suspensions in the form of spherical disks were transferred to a petri dish. Prepared disks were kept for $12 \mathrm{~h}$ to dry inside an oven, after which the weight of the flour disks was between $35-45 \mathrm{mg}$ and their moisture content was approximately $15 \%$. Different concentrations of essential oil from $M$. piperita $(0.0,0.5,1,1.5,2$ and $3 \mu \mathrm{L}$ in $1 \mathrm{~mL}$ of acetone) were placed on each disk separately and held for $20 \mathrm{~min}$ at room temperature to allow for evaporation of the acetone. In each petri dish, one flour disk was placed along with Twenty weighed adult insects were released in the containers and were kept there to be fed for three days. Following three days of treatment, both the insects and cowpea seed flour were weighed and nutritional indices were estimated as follow (Huang et al., 2000);

\section{Nutritional indices}

Nutritional indices were calculated (Tripathi et al., 2002) with some modifications: Relative Growth Rate $(\mathrm{RGR})=(\mathrm{A}-\mathrm{B}) /(\mathrm{B} \times$ day $)$, Where $\mathrm{A}=$ weight of live insects (mg) on the third day / number of live insects on the third day and $\mathrm{B}=$ original weight of insects $(\mathrm{mg}) /$ original number of insects. Relative consumption rate $(\mathrm{RCR})=\mathrm{D} /$ ( $\times$ day), Where $\mathrm{D}=$ biomass ingested $(\mathrm{mg}) /$ number of live insects on the third day. Percentage efficacy of conversion of ingested Food $(\mathrm{ECI})=\mathrm{RGR} / \mathrm{RCR} \times 100$. The feeding deterrent action was calculated as Feeding Deterrent Index (Isman, 2006): $(\% \mathrm{FDI})=[(\mathrm{C}-\mathrm{T}) / \mathrm{C}] \times 100$, Where $\mathrm{C}$ is the weight consumption food of control and $\mathrm{T}$ is the weight consumption food of treatment.

\section{Results}

Results of analysis of the M. piperita essential oil summarized and presented in Table 1. Results showed that eleven compounds were identified in the essential oil. The major components were found to be menthone $(28.9 \%)$, menthol $(28.5 \%)$, pulegone $(6.9 \%)$, menthofuran $(6.5 \%)$, 1,8-cineole (6.3\%) and $\beta$-caryophyllene (5.2\%).

The adult of $C$. maculatus was very susceptible to the $M$. piperia essential oil in the evaluation of fumigant toxicity. Comparison of the means of mortalities using Duncan's test showed that the essential oil had significantly different effects at different concentrations and that higher rates of mortality 
was observed in higher levels of concentration (Figure 1). The results showed that the means of mortalities with concentrations of 20 and $25 \mu \mathrm{L} / \mathrm{L}$ air performed the same while the means in 30,35 and $45 \mu \mathrm{L} / \mathrm{L}$ air concentrations were different. Concentration of $45 \mu \mathrm{L} / \mathrm{L}$ air has caused the highest mortality against $C$. maculatus adults (Figure 1).

The $\mathrm{LC}_{50}$ of $M$. piperita essential oil on the adults of $C$. maculatus was $25.70 \mu \mathrm{L} / \mathrm{L}$ air. Since the slope of regression line is positive, the increase of concentration logarithm leads to the increase of the number of mortality probit (Table 2).

The $\mathrm{LT}_{50}$ of 100,200 and $500 \mu \mathrm{L} / \mathrm{L}$ air from $M$. piperita essential oil on C. maculatus adults was calculated as 3.29, 2.74 and $1.89 \mathrm{~h}$, respectively. Comparison of the three concentrations and 95\% upper and lower confidence limits using Preisler method showed that 100 and $200 \mu \mathrm{L} / \mathrm{L}$ air concentrations acted the same; however, $500 \mu \mathrm{L} / \mathrm{L}$ air con- centrations were significantly different from the two others. Comparison of the confidence interval of three concentrations using Preisler method indicated that LT $_{50}$ of 100 and $200 \mu \mathrm{L} / \mathrm{L}$ air concentrations was not significantly different while $\mathrm{LT}_{50}$ at $500 \mu \mathrm{L} / \mathrm{L}$ air was significantly different with the two other concentrations (Table 3 ).

The obtained results reveal that the effect of essential oil has declined by the passage of time. The calculated $\mathrm{LT}_{50}$ so as to study the persistence of $M$. piperita essential oil on $C$. maculatus adults was 5.44 days. LT $_{50}$ of $M$. piperita essential oil at $500 \mu \mathrm{L} / \mathrm{L}$ air concentration was calculated as 5.44 days and in day 15 , the percent of mortality in treatment and control groups have been the same (Table 4).

One would say based on the obtained results of repellency experiment, the essential oil of $M$. piperita was repellent at 90,180 and $360 \mu \mathrm{L} / \mathrm{L}$ air concentration and the repellency

Table 1. Major chemical composition (\%) of essential oil of Mentha piperita L.

\begin{tabular}{|c|c|c|c|}
\hline & Compound & Retention time & Percentage \\
\hline 1 & Limonene & 928 & 2.9 \\
\hline 2 & 1,8-cineole & 932 & 6.3 \\
\hline 3 & Menthone & 965 & 28.9 \\
\hline 4 & Menthofuran & 979 & 6.5 \\
\hline 5 & Isomenthone & 1002 & 4.5 \\
\hline 6 & Linalool & 1027 & 3.5 \\
\hline 7 & $\beta$-caryophyllene & 1030 & 5.2 \\
\hline 8 & Terpinen-4-ol & 1082 & 2.2 \\
\hline 9 & Menthol & 1120 & 28.5 \\
\hline 10 & Pulegone & 1143 & 6.9 \\
\hline 11 & $\alpha$-terpineol/borneol & 1160 & 2.9 \\
\hline & Total & & 98.3 \\
\hline
\end{tabular}

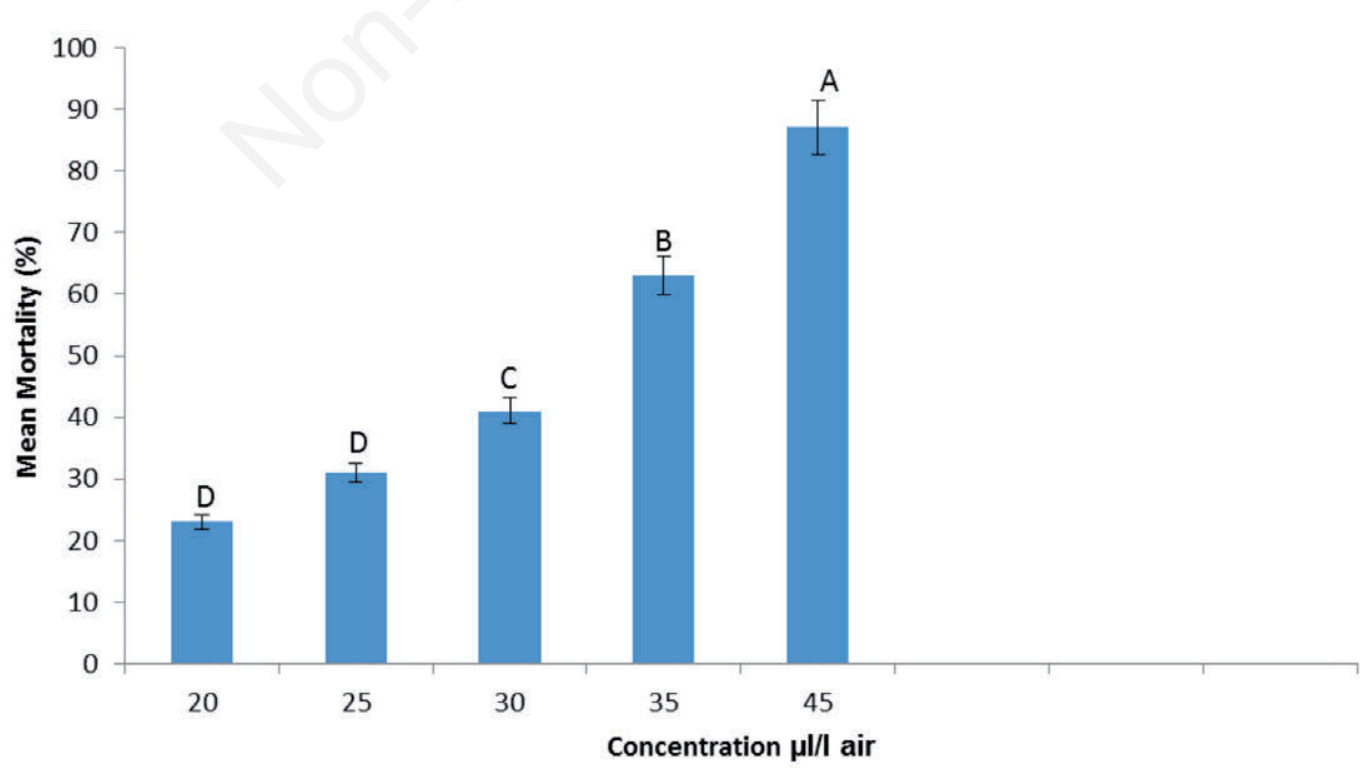

Figure 1. The means mortality of $C$. maculatus adults at different concentration of $M$. piperita essential oil. Different letters over columns indicate significant differences according to Duncan's test at $\mathbf{P}=\mathbf{0 . 0 5}$. Columns with the same letter are not significantly different. 
index increases by the increase of concentration percent (Table 5). Based on the means of repellency percent, $M$. piperita essential oil has the same effects at 180 and $360 \mu \mathrm{L} / \mathrm{L}$ air concentrations and falls into the same group. However, it has lower repellency effect at $90 \mu \mathrm{L} / \mathrm{L}$ air which falls into different group. According to the comparison of each concentration of M. piperita oil using categorizing method of repellency effect, it can be concluded that the essential oil has significantly different at $90 \mu \mathrm{L} / \mathrm{L}$ air concentration compared to 180 and $360 \mu \mathrm{L} / \mathrm{L}$ air. Also, the two concentrations of 180 and 360 $\mu \mathrm{L} / \mathrm{L}$ air are more repellent and act better (Table 5).

Relative Growth Rate (RGR), Relative Consumption
Rate (RCR), Efficiency of Conversion of Ingested food (ECI) and Feeding Deterrence Index (FDI) were showed in Table 6 . The results of variance analysis showed that $M$. piperita essential oil has affected the RGR, RCR and FDI of C. maculatus adults and it was concentration dependent. The concentration difference with control group was considerable (Table 6). The results of variance analysis showed that the effects of $M$. piperita essential oil are not significantly different at different concentrations on the index of ECI. In general, one would contribute the main element of caused effects in RGR and RCR to the effects of food deterrent index (Table 6).

Table 2. Result of the M. piperita oil probit analysis to calculate $\mathrm{LC}_{50}$ and $\mathrm{LC}_{90}$ values.

\begin{tabular}{|c|c|c|c|c|}
\hline $\mathrm{LC}_{50}(\mu \mathrm{L} / \mathrm{L} \text { air })^{*}$ & $\mathrm{LC}_{90}(\mathrm{\mu L} / \mathrm{L}$ air $)$ & Slope $\pm S E$ & Intercept & $X^{2}(d f=1)$ \\
\hline $25.70(21.01-29.41)$ & $63.04(52.76-85.55)$ & $12.55 \pm 1.12$ & -9.29 & 3265.23 \\
\hline
\end{tabular}

*95\% lower and upper fiducially limits are shown in parenthesis.

Table 3. $\mathbf{L T}_{50}$ values of fumigant toxicity of $M$. piperita essential oil against adults of $C$. maculatus.

\begin{tabular}{lccccc} 
Concentration ( $\mathrm{ML} / \mathrm{L}$ air) & LT50 (days)* & $\mathbf{X}^{2}(\mathrm{df}=1)$ & $\begin{array}{c}\text { Slope } \pm \text { SE } \\
\text { Intercept }\end{array}$ & $\begin{array}{c}\text { Comparison using } \\
\text { Preisler method }\end{array}$ \\
\hline 100 & $3.29(2.83-3.63)$ & 44.92 & $9.56 \pm 1.29$ & -4.45 & $\mathrm{a}$ \\
200 & $2.74(2.23-3.12)$ & 30.76 & $10.57 \pm 1.74$ & -4.38 & $\mathrm{a}$ \\
\hline 500 & $1.89(1.32-2.36)$ & 14.20 & $11.96 \pm 2.77$ & -3.82 & $\mathrm{~b}$ \\
\hline
\end{tabular}

*95\% lower and upper fiducially limits are shown in parenthesis.

Table 4. Calculated $\mathrm{LT}_{50}$ values for the persistence of fumigant toxicity in $M$. piperita essential oil at concentration of 500 ( $\mu \mathrm{L} / \mathrm{L}$ air) on C. maculatus.

\begin{tabular}{lcccc} 
Concentration ( $\mathrm{ML} / \mathrm{L}$ air) & $\mathrm{LT}_{50}$ (days) & $\mathrm{X}^{2}(\mathrm{df}=1)$ & Slope \pm SE & Intercept \\
500 & $5.44(4.61-6.17)$ & 126.22 & $-4.65 \pm 0.33$ & 4.02 \\
\hline
\end{tabular}

Table 5. The results of repellency effect of $M$. piperita essential oil against $C$. maculatus adults.

\begin{tabular}{lccccc} 
Concentration ( $\mathrm{ML} / \mathrm{L}$ air) & $\begin{array}{c}\text { Mean repellent } \\
\text { indexes } \pm \text { SD }\end{array}$ & SD -1 & SD + 1 & $\begin{array}{c}\text { Effect } \\
\pm \text { SD }\end{array}$ & Rean repellent $(\%)$ \\
90 & $0.27 \pm 0.03$ & 0.81 & 1.18 & Repellent & $71.64 \pm 5.62^{\mathrm{a}}$ \\
180 & $0.21 \pm 0.09$ & 0.80 & 1.19 & Repellent & $77.60 \pm 6.08^{\mathrm{b}}$ \\
\hline 360 & $0.11 \pm 0.04$ & 0.85 & 1.12 & Repellent & $87.76 \pm 0.96^{\mathrm{b}}$ \\
\hline
\end{tabular}

SD, standard deviation. Means with the same letter for each column aren't significant differences.

Table 6. Total average effects of essential oil from $M$. piperita at various concentrations on nutritional indices of adults of $C$. maculatus.

\begin{tabular}{|c|c|c|c|c|}
\hline Concentration ( $\mu \mathrm{L} /$ disk) & RGR (mg/mg/day) & RCR (mg/mg/day) & ECI (\%) & FDI (\%) \\
\hline 0.00 (Control) & $0.056 \pm 0.001^{\mathrm{a}}$ & $0.31351 \pm 0.012^{\mathrm{a}}$ & $25.276 \pm 8.323^{\mathrm{a}}$ & - \\
\hline 0.5 & $0.036 \pm 0.001^{\mathrm{ab}}$ & $0.235 \pm 0.014^{\mathrm{ab}}$ & $13.760 \pm 7.431^{\mathrm{b}}$ & $40.298 \pm 20.710^{a}$ \\
\hline 1 & $0.033 \pm 0.002^{b}$ & $0.215 \pm 0.012^{\mathrm{bc}}$ & $13.243 \pm 6.220^{\mathrm{b}}$ & $45.889 \pm 15.112^{\mathrm{a}}$ \\
\hline 1.5 & $0.025 \pm 0.002^{b}$ & $0.174 \pm 0.013^{\mathrm{bc}}$ & $10.231 \pm 5.462^{\mathrm{c}}$ & $52.705 \pm 21.256^{\mathrm{ab}}$ \\
\hline 2 & $0.021 \pm 0.001^{b}$ & $0.120 \pm 0.020^{\mathrm{bc}}$ & $8.541 \pm 2.256^{\mathrm{cd}}$ & $62.949 \pm 22.014^{\mathrm{ab}}$ \\
\hline 3 & $0.015 \pm 0.003^{b}$ & $0.106 \pm 0.035^{c}$ & $4.235 \pm 1.216^{\mathrm{d}}$ & $87.829 \pm 5.235^{b}$ \\
\hline
\end{tabular}

RGR, relative growth rate; RCR, relative consumption rate; ECI, efficiency of conversion of ingested food; FDI, feeding deterrence index.

Dissimilar letters in each column with using Duncan test at level of 5\% together have significant differences. 


\section{Discussion and Conclusions}

Nowadays, many studies have been done for evaluation of susceptibility of stored product insect pests specially Callosobruchus maculatus to plant essential oils. For example, the antifeedant activities of Citrus reticulate Blanco, C. limon L. and C. aurantium L. essential oils against eggs, larvae and adults of $C$. maculatus were studied by Saeidi et al (2014). The results showed that the effect of different concentrations of the essential oil vapors on egg hatchability as well as larval and adult mortality was found to be significant. Citrus reticulata and C. aurantium oils were more toxic on egg hatchability than $C$. limon extract and caused higher mortality on larvae as well. There was no significant difference between essential oils in terms of adult mortality. The adult beetles were also exposed to the concentrations of $18.5,37,55.5$ and $74 \mu \mathrm{L} / \mathrm{L}$ air. At the highest concentration $(74 \mu \mathrm{L} / \mathrm{L}$ air $), C$. aurantium oil caused $100 \%$ mortality after a $6 \mathrm{~h}$ exposure, but the oils from C. reticulata and C. limon caused $38 \%$ and $62 \%$ mortality, at the identical exposure time, respectively. In the study of Saeidi (2014), the essential oils of Eucalypts globulus and Eucalyptus camaldulensis against C. maculatus were evaluated. The results revealed that E. globulus oils were more effective than $E$. camaldulensis oils, by significantly decreasing the RGR, RCR and ECI. Both of plant essential oils, with the same activity, increased FDI as the oil concentration was increased, showing high feeding deterrence activity against C. maculatus. Generally, antifeedant activity of $E$. globulus was more effective than E. camaldulensis. In the other study, fumigant toxicity of essential oils extracted from Laurus nobilis L. and Myrtus communis L. was assessed on adults and eggs stage of Callosobruchus maculatus. The results indicated that $\mathrm{LC}_{50}$ values for L. nobilis and M. communis for adults of the beetle were calculated to be 71.782 and 44.138 micro liter per liter of air and the $\mathrm{LC}_{95}$ values were calculated to be 216.278 and 141.716 micro liter per liter of air, respectively. The $\mathrm{LC}_{50}$ values for L. nobilis and M. communis for eggs of the beetle were calculated to be 63.994 and 38.371 microliter per liter of air, respectively (Senfi et al., 2014). The respiratory toxicity of tangerine essential oil on the mortality rate of the adults of Callosobruchus maculatus was evaluated by Mobki et al. (2014). The essential oil of tangerine exhibited strong respiratory toxicity against $C$. maculatus adults with a $\mathrm{LC}_{50}$ value of $88.93 \mu \mathrm{L} / \mathrm{L}$ air and $\mathrm{LC}_{95}$ value of $205.54 \mu \mathrm{LL}$ air. The results of mentioned studies have supported present study for susceptibility of $C$. maculatus to plant essential oils.

The essential oils Mentha species comprise of metabolic compositions such as menhone and menthol compositions and include toxic effects against stored product pests (Tandorost \& Karimpour, 2012).

In the present study, fumigant toxicity and its persistency, repellent and nutritional indices of essential oils from M. piperita were assessed against $C$. maculatus. There are many researches that provide sound evidences for insecti- cidal activities of Mentha species that parallel with present results; the repellency of $M$ pulegium $\mathrm{L}$. essential oil against Plodia interpunctella Hubner (Lepidoptera: Pyralidae) was showed (Saeidi and Hassanpour, 2014). The results showed that the main components such as cymol, 1,8-cineole, terpineol and $\alpha$-pinene cause toxic effects and repellency (Tapondjou et al., 2005). The essential oils from Eucalyptus intertexta, Eucalyptus sargentii and Eucalyptus camaldulensis were tested against cowpea seed beetle, Callosobruchus maculatus(F.), Sitophilus oryzae (L.) and T. castaneum. The mortality of 1 to 7 day old adults of the insects increased with concentration from 37 to $926 \mu \mathrm{L} / \mathrm{L}$ air and with exposure time from 3 to $24 \mathrm{~h}$. The $\mathrm{LC}_{50}$ values of Eucalyptus essential oils tested in this study were ranged from 2.55 to $33.50 \mu \mathrm{L} / \mathrm{L}$ air (Negahban $\&$ Moharramipour, 2006). Oviposition deterrence and persistence of Thymus persicus (Roniger ex Reach F.) and Prangos acaulis (Dc.) essential oils against C. maculatus adults were illustrated in the studies of Taghizadeh Saroukolai and Moharramipour (2011). Oviposition deterrence was assessed at 6 concentrations from 360 to 7140 ppm and with five replications. Results showed that oviposition deterrence of both essential oils were increased with increase of oil concentration and higher deterrence was significantly recorded in $P$. acaulis. $\mathrm{LT}_{50}$ values showed that the speed of mortality in $P$. acaulis was significantly faster than that of $T$. persicus. The respiratory toxicity of $T$. persicus essential oil on $C$. maculates was more stable than that of $P$. acaulis.

In the current study, the main included composition of M. piperita essential oil i.e. menthone was detected using GCMS and it is supported by many research that menthone has been main components of many mentha species (Sefidkon et al., 2014). The researches have indicated that herbal monoterpene such as menthone and menthol have shown to be successful in initial analysis of fumigation toxicity (Saeidi et al., 2014). The insecticidal propriety of many essential oils is mainly attributed to monoterpenes which are typically volatile and rather lipophilic compounds that can penetrate into insects rapidly and interfere with their physiological functions. Due to their high volatility, they have fumigant and gaseous action which are very important in controlling the stored-product insects. Jointly or independently, these compounds are involved in the bioefficacy of the essential oils used with a range of effects i.e. insecticidal, repellent, antifeeding, and ovicidal activities (Aliakbari et al., 2010). It can be concluded that the toxicity of $M$. piperita essential oil against mentioned pests is related to their major components such as menthone. some researchers have demonstrated that essential oils have neurotoxic, citotoxic, phototoxic and mutagenic action among others in different organism (Isman et al., 2011), and the essential oils act at multiple levels in the insects, so the possibility of generating resistance is little probable (Saeidi \& Hassanpour, 2014). For all these reasons, we can infer that the plant essential oils especially $M$. piperita essential oil could be considered as a natural alternative in the control of stored grains insects such as $C$. maculatus. 


\section{References}

ALI A., RIZVI P.O. 2008 - Bio-efficacy of some plant leaf extracts against mustard aphid, Lipaphis erysimikalt on Indian mustard, Brassica juncea. J. Plant. Protec. Res. $50: x-y$.

ALIAKBARI J., FALLAHZADEH M., GHASEMI A., ABDIZADEH R. 2010 - Insecticidal activity of essential oil from Thymus daenensis Celak against Tribolium confusum Dur. - Proceeding of the 19th Iranian Plant Protection Congress, July 31-August 3, 2010. Iranian Research Institute of Plant Protection, Tehran, Iran.

ARTHUR F.H., HIGHLAND H.A., MULLEN M.A. 1991 Efficiency and longevity of two commercial sex pheromone lures for indianmeal moth and almond moth (Lepidoptera: Pyralidae). - J. Econ. Entomol. 26: 64-68.

ARTHUR F.H., SIMONAITIS R.A., THRONE J.E., ZEHNER J.M. 1990 - Evaluation of chlorpyrifos-methyl and chlorpyriphos-methyl plus methoprene as protectants of stored corn: small bin tests. - J. Econ. Entomol. 83: 1114-1121.

AYVAZ A., SAGDIC O., KARABORKLU S., OZTURK I. 2010 - Insecticidal activity of the essential oils from different plants against three stored-product insects. - J. Ins. Sci. 10: 21.

BAHL F.S., AVERBECK D., AVERBECK B., IDAOMAR M., 2008 - Biological effects of essential oils a review. Food Chem. Toxicol. 46: 446-475.

BENHALIMA H., CHAUDHRY M.Q., MILLS K.A., PRICE N.R., 2004 - Phosphine resistance in storedproduct insects collected from various grain storage facilities in Morocco. - J. Stored Prod. Res. 40: 241-249.

BENZI V., STEFANAZZI N., FERRERO A., 2009 Biological activity of essential oils from leaves and fruits of pepper tree (Schinus molle L.) to control rice weevil (Sitophilus oryzae L.). - Chilean J. Agri. Sci. 69: 154-159.

EBADOLLAHI A., MAHBOUBI M., 2011 - Insecticidal activity of essential oil isolated from Azilia eryngioides (Pau) Hedge Et Lamond against two beetle pests. Chilean J. Agri. Res. 71: 406-411.

HALDER J., SRIVASTAVA C., DUREJA P., 2010 - Effect of methanolic extracts of periwinkle (Vinca rosea) and bottlebrush (Callistemon lanceolatus) alone and their mixtures against neonate larvae of gram pod borer (Helicoverpa armigera). - Indian J. Agri. Sci. 80: 820-823.

HANSEN L.S., JENSEN K.M.W. 2002 - Effect of temperature on parasitism and host-feeding of Trichogramma turkestanica (Hymenoptera: Trichogrammatidae) on Ephestia kuhniella (Lepidoptera: Pyralidae). J. Econ. Entomol. 95: 50-56.

HUANG F., SUBRAMANYAM B., 2005 - Management of five stored-product insects in wheat with pirimiphosmethyl and pirimiphos-methyl plus synergized pyrethrins. - Pest Manag. Sci. 61: 356-362.

ISMAN M.B. 2006. Botanical insecticide deterrents in modern agriculture and increasingly regulated world. Annu. Rev. Entomol. 5: 45-66.
ISMAN M.B., MACHIAL C.M., 2006 - Pesticides based on plant essential oils: from traditional practice to commercialization. In: RAI M., CARPINELLA M.C., (eds.). Naturally occurring bioactive compounds. Adv. Phytomed. 3: 29-44.

LOPEZ M.D., JORDAN M.J., PASCUAL-VILLALOBOS M.J., 2008 - Toxic compounds in essential oils of coriander, caraway and basil active against stored rice pests. J. Stored Prod. Res. 44: 273-278.

MOBKI M., SAFAVI S.A., SAFARALIZADEH M.H., 2014 - Evaluation of fumigant toxicity of the essential oil of Citrus reticulata fruit peels and synergistic effect of diethyl maleate and acetone in the control of the adult cowpea weevils, Callosobruchus maculatus F. (Col.: Bruchidae). - Iran. J. Med. Arom. Plants 30: 292-298.

MOHANDASS S., ARTHUR F.H., ZHU K.Y., THRONE J.E., 2007 - Biology and management of Plodia interpunctella (Lepidoptera: Pyralidae) in stored products. J. Stored Prod. Res. 43: 302-311.

NAYAMADOR W.S., KETOH G.K., AMEVOIN K., NUTO Y., KOUMAGLO H.K., GLITHO I.A., 2010 Variation in the susceptibility of two Callosobruchus species to essential oils. - J. Stored Prod. Res. 46: 48-51.

NEGAHBAN M., MOHARRAMIPOUR S. 2006 Repellent activity and persistence of essential Oil from Artemisia sieberi besser on three stored-product insect species. - Iran. J. Med. Arom. Plants. 22: 293-302.

OGENDO J.O., KOSTYUKOVSKY M., RAVID U., MATASYOH J.C., DENG A.L., OMOLO E.O., KARIUKI S.T., SHAAYA E., 2008 - Bioactivity of Ocimum gratissimum L. oil and two of its constituents against five insects attacking stored food products. - J. Stored Prod. Res. 44: 328-334.

PARK I.K., KIM J.N., LEE Y.S., LEE S.G., YOUNG J., AHN, Y.A., SHIN S.C., 2008 - Toxicity of plant essential oils and their components against Lycoriella ingenua (Diptera: Sciaridae). - J. Econ. Entomol. 101: 139-144.

REHMAN M., MOHAMMAD H., AHMED F., MANAS A., SKARI M., 1992 - Screening of tropical plants for the presence of bioactive compounds. - Pertanika J. Trop. Agricult. Sci. 15: 131-135.

SAEIDI K., 2014 - Antifeedant and growth inhibitory activities of essential oils from Eucalyptus globulus and Eucalyptus camaldulensis on Callosobruchus maculatus (Coleoptera: Chrysomelidae). - Plant Protect. J. 6: 391-400.

SAEIDI K., HASSANPOUR B., 2014 - Efficiency of Mentha piperita L. and Mentha pulegium L. essential oils on nutritional indices of Plodia interpunctella Hübner (Lepidoptera: Pyralidae). - J. Entomol. Acarol. Res. 47: 13-17.

SAEIDI K., YOUSEFI M., 2013 - Essential oil and antifeedant activity of Zataria multiflora Boiss and Thymus daenensis Celak on Plodia interpunctella Hubner. - Int. J. Med. Arom. Plants. 3: 151-158.

SAEIDI M., MOHARRAMIPOUR S., SEFIDKON F., 2014 - Chemical composition and fumigant toxicity of three citrus essential oils against eggs, larvae and adults of 
Callosobruchus maculatus (Col.: Bruchidae). - J. Entomol. Soc. Iran 34: 17-25.

SENFI F., SAFARALIZADEH M.H., SAFAVI S.A., ARAMIDAE S., 2014 - Evaluation of fumigant toxicity of Laurus nobilis L. and Myrtus communis L. essential oils on eggs and adult stage of the Cowpea weevil, Callosobruchus maculatus F. (Col.: Bruchidae). - Iran. J. Med. Arom. Plants 30: 216-222.

TAGHIZADEH-SAROUKOLAI A., MOHARRAMIPOUR S., 2011 - Oviposition deterrence and persistence of essential oils from Thymus persicus (Roniger ex Reach F.) compared to Prangos acaulis (Dc.) Bornm against Callosobruchus maculatus F. in laboratory. - Iran. J. Med. Arom. Plants. 27: 202-211.

TAGHIZADEH-SAROUKOLAI A., MOHARRAMIPOUR S., MESHKATALSADAT M.H., 2010 - Insecticidal properties of Thymus persicus essential oil against Tribolium castaneum and Sitophilus oryzae. - J. Pest. Sci. 83: 3-8.
TANDOROST R., KARIMIPOUR Y., 2012 - Evaluation of fumigant toxicity of orange peel Citrus sinensis (L.) essential oil against three stored product insects in laboratory condition. - Munis Entomol. Zool. 7: 352-358.

TAPONDJOU A.L., ADLER C., FONTEM D.A., BOUDA H., REICHMUT C., 2005 - Bioactivities of cymol and essential oils of Cupressuss empervirens and Eucalyptus saligna against Sitophilus zeamais (Motschulsky) and Tribolium confusum (du Val). - J. Stored Prod. Res. 41: 91-102.

TRIPATHI A.K., PRAJAPATI V., AGGARWAL K.K., KUMAR S., 2002 - Bioactivity of I-carvone, d-carvone and dihydrocarvone towards three stored product beetles. - J. Econ. Entomol. 96: 1594-1607.

WARKENTIN J., VANDER W., SILVA K., LABADIE P., 1991 - Ethnopharmacognostical survey of Azadirachta indica and Azadirachta juss. - J. Ethnopharmacol. 35: $1-24$. 